\title{
Sobre la paz relativa
}

Propósito de un constitucionalismo ciudadano

Raúl Gustavo Ferreyra ${ }^{1}$

"L'architecture de la paix Repose sur le monde entier". Paul Éluard: Le Visage de la paix (XXVI] (1951)

\section{§ 1. Preámbulo}

La existencia con vida y cognición nos ha sido impuesta a los seres humanos. La cabal comprensión del hombre brinda el más espléndido espectáculo en la maravillosa escena del mundo ${ }^{2}$. Coexistir, por tanto, o existir con otros individuos en común sólo se hace factible en tanto pueda conjugarse una totalidad o mayoría de ciudadanos más poderosa que cada uno de los ciudadanos juzgados en su singularidad inalienable; conjugación, además, que deberá poseer como atribución el hecho indisputado de su unión mayoritaria frente a la individualidad arbitraria o discrecional que cualquiera de éstos deseare ejercer. Llamase, pues, al poderío emergente de la congregación de las individualidades ciudadanas "Derecho constitucional" -que emerge del artefacto "constitución" y que nada tiene de natural- el cual autoriza una posible ordenación y un semejante desarrollo de la coexistencia comunitaria; y al poderío individual, "fuerza bruta"3. Reducir el ámbito del más fuerte, que nadie quedase librado a la fuerza bruta irresistible individual o

\footnotetext{
1 Profesor titular de Derecho Constitucional, Facultad de Derecho, UBA. Doctor en Derecho (UBA).

2 Pico Della Mirandola, Giovanni: Discurso sobre la dignidad del hombre, Universidad Nacional de Cuyo, Facultad de Filosofía y Letras, Instituto de Letras Modernas, Mendoza, 1972, p. 41.

3 Freud, Sigmund: El malestar en la cultura, Madrid, Alianza, 2010, pp. 65, 86, 87.
} 
a la franca y desvalida merced de los poderes fácticos, se reporta como el propósito de la lengua del Derecho constitucional, que debe articular la paz, único proceso que autoriza la coexistencia de ciudadanos con igual y semejante dignidad.

La idea básica propuesta en este texto descansa en comprender a la lengua del Derecho constituyente del Estado como un código para la paz. Tal Derecho constitucional, emanación fundamental de un orden jurídico específico, artefactual y estatal, debe aspirar a constituir la lengua que sostiene y desarrolla la unidad, en paz, de una comunidad determinada.

Hablar de una lengua del Derecho constitucional tiene sentido porque lo "humano" surge en la historia evolutiva del linaje homínido al que pertenecemos, al surgir el lenguaje ${ }^{4}$. En el ámbito de la existencia humana, el dominio de la realidad, en buena parte, puede quedar vinculado a la configuración del lenguaje $e^{5}$. Entonces, ejercer dominio sobre la producción y variación de las palabras del orden jurídico, aunque no define por completo el dominio de la realidad, se comporta como un agente para la creación, el mantenimiento o el cambio de las prescripciones jurídicas que lo componen.

Esa lengua, la lengua del Derecho constitucional, configura el texto fundamental para la existencia en paz de los ciudadanos y servidores públicos. Ambos, para lograr que rijan o que tengan eficacia los enunciados de la lengua constituyente del Estado, deben comprenderse en la escena del dominio lingüístico y deben producir una asociación recurrente, intensa y prolongada, en la aceptación y desarrollo de las determinaciones prescriptivas sobre la conducta humana. Así, en el marco de

\footnotetext{
4 Maturana, Humberto: "Lenguaje y realidad. El origen de lo humano", en Archivos de Biología y Medicina Experimentales, n²22, Santiago de Chile, 1989, pp. 77-81.

5 Una de las acepciones del vocablo "lengua”, según el Diccionario de la Real Academia Española, es "Sistema de comunicación verbal y casi siempre escrito, propio de una comunidad humana". De acuerdo con la misma fuente, una de las opciones lexicográficas de "lenguaje": "lengua (sistema de comunicación verbal)". Asumo, desde luego, las diferencias que existen. No obstante, por motivos que el lector podrá comprender, empleo indistintamente las voces "lengua" y "lenguaje".
} 
una escritura sin despotismos, la realidad comunitaria se debe encontrar abierta al discurso que contiene las palabras constituyentes. La gobernanza de tal realidad, por lo tanto, queda remitida al consenso, mayor o menor, sobre el marco de referencia que ha de referirse o preferirse a la mutualidad de las determinaciones sobre la conducta humana. De manera coherente, pues, la existencia de los ciudadanos en la formación precisa de la lengua constituyente del Estado debería configurar el propio dominio de realidad. ${ }^{6}$

La filiación de estas escrituras laicas es de carácter normativista; quiero decir, que responde a un modelo de Derecho en el que solamente se reconoce como tal a toda combinación de enunciados normativos y no normativos producidos por el sujeto autorizado para crear o realizar el orden jurídico de que se tratare, cuya cualidad básica descansa en la coerción; así, pues, el Derecho debería consagrarse en la razón de la fuerza del Estado. Bien entendido, que esa comprensión se ejecuta en el ámbito de un "constitucionalismo ciudadano", en el que la dirección suprema de la ordenación estatal que debe producirla reside en los ciudadanos que integran el pueblo, quienes por lo general poseen ideas diversas y en muchas ocasiones no coincidentes. La ejercen por representación (intermediada siempre por el sufragio y el representante) u, ocasionalmente, en forma directa. En sentido formal, un ciudadano es un elector porque puede participar en la producción de la suma regla, a

6 Desde el punto de vista normativo, al respecto hay dos simientes muy interesantes; una del siglo XVIII y otra del XX. En el art. 377 de la Constitución de Francia de 1795, se dispuso: "El pueblo francés deposita la presente Constitución en la fidelidad del Cuerpo legislativo, del directorio ejecutivo, de los administradores y jueces; a la vigilancia de los padres de familia, a las esposas y a las madres, al efecto de los jóvenes ciudadanos, a la cordura de todos los franceses". Por su parte, en el art. 41 de la Constitución de Colombia de 1991 se ordena: "En todas las instituciones de educación, oficiales o privadas, serán obligatorios el estudio de la Constitución y la Instrucción Cívica. Asimismo se fomentarán prácticas democráticas para el aprendizaje de los principios y valores de la participación ciudadana. El Estado divulgará la Constitución". Desde la dogmática científica, en la literatura especializada, la obra de Peter Häberle Cartas pedagógicas a un joven constitucionalista (Niedersachsen, Alemania, European Research Center of Comparative Law, 2013) constituye una obra erudita, original y francamente fundamental en la instrucción y educación del Derecho constitucional. 
condición de que sea convocado y se confiera reconocimiento a determinados derechos básicos. Pese a la inexistencia del mandato imperativo, la ilusión de la democracia directa lleva a considerar que cada ciudadano tiene una "millonésima" cuota del poder para hacer la constitución, reformarla y, sobre todo, intentar una defensa contra los abusos de las autoridades constituidas a cargo de los poderes públicos y de los cada vez más emergentes poderes privados.

Aquí no se expone una teoría general de la paz, porque hay un consenso extendido sobre la ausencia de dicho cuerpo doctrinal. Sin embargo, no se puede dejar de aseverar que un orden jurídico constitucional dejaría de existir en el momento preciso que dejare de garantizar la paz social. El Estado constitucional es el único instrumento que puede disponer de la razón pública y de la experiencia humana (por intermedio de sus servidores públicos y ciudadanos) para procurar una pacificación relativa en la comunidad. Al Estado constitucional lo instituyen ciudadanos que deben ser considerados igualmente libres y también lo sostienen por intermedio del proceso de la democracia (un mero consenso general sobre reglas generales respecto de quien ha de gobernar) que abre, regula, capta y discierne la prevalencia circunstancial de un estado de opinión ciudadano mayoritario, hasta nuevo aviso ${ }^{7}$. Así, la norma constitucional, procesal por eminencia, puede ser una llave verdadera para instituir e ilustrar el proceso de la paz social.

Además, este texto no se desenvuelve sobre la descripción concreta de un orden jurídico en particular. El único aliento reconocible reside en mi "ciudadanía sudamericana". Quizá pueda aportar un grano de arena fundado en mi naturaleza de

\footnotetext{
Debo admitir que la tesis primitiva "un representante para cada opinión, ergo, un ciudadano, un voto", no resulta de fácil elaboración y desarrollo. Porque en nuestras frágiles democracias en América del Sud no es infrecuente que el elector-ciudadano sufrague inclinado hacia "lo menos malo" o "en contra de alguien" más que sintiéndose realmente orientado en su decisión política hacia alguien que lo represente. Posiblemente, en la anterior insinuación descanse una de las mayores debilidades de la democracia, que indica que ella es más una meta inalcanzable que un camino concreto e iluminado.
} 
observador externo del orden político y jurídico de los Estados de América del Sud. No obstante, no soy neutral porque soy parcial, porque milito activamente hacia la paz relativa. La paz existe o la paz no existe; no es una epifanía o una revelación divina. Los hombres deben construirla y sostenerla con fundamentos y progresividad. Otras consideraciones serían anécdotas improbables o simples desvaríos.

Al respecto, las dicciones constitucionales de cada uno de los Estados sudamericanos son sumamente interesantes:

(i) El artículo 22 de la Constitución Política de Colombia de 1991 determina: "La paz es un derecho y un deber de obligatorio cumplimiento".

(ii) El artículo 4 de la Constitución de la República Federativa de Brasil de 1998, disposición en la que se determina que sus relaciones internacionales se rigen por los siguientes principios: "VI. Defensa de la paz".

(iii) En la Constitución de Ecuador de 2008, en el artículo 3 se dispone que son deberes primordiales del Estado: “... 8. Garantizar a sus habitantes el derecho a una cultura de paz...”.

(iv) Por su mágica antigüedad, se destaca también el milagroso Preámbulo de la Constitución federal de la Argentina, vigente desde 1853: "Nos los representantes del pueblo de la Nación Argentina, (...) con el objeto de (...) consolidar la paz interior, (...) para nosotros, para nuestra posteridad, $y$ para todos los hombres del mundo que quieran habitar en el suelo argentino: invocando la protección de Dios, fuente de toda razón y justicia: ordenamos, decretamos y establecemos esta Constitución, para la Nación Argentina".

(v) La República del Paraguay, en el artículo 145 de su Constitución de 1992, dispone que “... en condiciones de igualdad con otros Estados, admite un orden jurídico supranacional que garantice la vigencia (...) de la paz...".

La paz respecto de la cual se escribe aquí es la "paz relativa", en un doble sentido. Porque es "relativa" a una comunidad 
determinada ${ }^{8}$, clarísima expresión de la soberanía política y la autodeterminación. En ese sentido, la paz interna constituye un presupuesto para la libertad, la igualdad y la solidaridad, porque al concentrarse en la coexistencia hace presuponer la futurible existencia del resto de los bienes. Desde luego, se requiere de un Estado soberano para fijar los procesos que resuelvan los conflictos, en muestra de una clara de determinación del monopolio, concentración y disciplina de la fuerza 9 . Un Estado, además, que encierra y se arroga la administración legítima de la fuerza en un tiempo y espacio determinados. También la "paz

8 En septiembre de 2015, más de 150 jefes de Estado y de Gobierno se reunieron en la Cumbre del Desarrollo Sostenible en la que aprobaron la Agenda 2030. Esta Agenda contiene 17 objetivos de aplicación universal que, desde el 1 de enero de 2016, rigen los esfuerzos de los Estados para lograr un mundo sostenible en el año 2030. Los Objetivos de Desarrollo Sostenible (ODS) presentan la singularidad de sugerir, estimular y apoyar a que todos los Estados, ya sean que posean riqueza yacente o a crearse o sean desposeídos, a adoptar medidas para promover la prosperidad al tiempo que protegen el mundo. Los ODS no son jurídicamente obligatorios, pero se aguarda que los gobiernos los adopten como propios y establezcan marcos estatales para su concreción. En el "ODS" número 16 se establece: Promover sociedades, justas, pacíficas e inclusivas".

Recuérdese, además, que en el artículo 1 de la Carta de las Naciones Unidas (firmada el 26 de junio de 1945) se dispone que: "Los propósitos de las Naciones Unidas son: (1) Mantener la paz y la seguridad internacionales, y con tal fin: tomar medidas colectivas eficaces para prevenir y eliminar amenazas a la paz, y para suprimir actos de agresión u otros quebrantamientos de la paz; y lograr por medios pacíficos, y de conformidad con los principios de la justicia y del derecho internacional, el ajuste 0 arreglo de controversias o situaciones internacionales susceptibles de conducir a quebrantamientos de la paz. (2) Fomentar entre las naciones relaciones de amistad basadas en el respeto al principio de la igualdad de derechos y al de la libre determinación de los pueblos, y tomar otros medidas adecuadas para fortalecer la paz universal. (3) Realizar la cooperación internacional en la solución de problemas internacionales de carácter económico, social, cultural o humanitario, y en el desarrollo y estímulo del respeto a los derechos humanos y a las libertades fundamentales de todos, sin hacer distinción por motivos de raza, sexo, idioma o religión. (4) Servir de centro que armonice los esfuerzos de las naciones por alcanzar estos propósitos comunes".

Las palabras son importantes para la existencia de los seres humanos, pero no son suficientes. Son numerosas las guerras desatadas desde 1945, las que todavía mantienen su degradante vigencia y peor todavía: Ios sujetos irracionales que persiguen que haya nuevas 0 se profundicen las actuales. ¡No por eso se debe renunciar al valor y la importancia de las palabras!

9 V. Kriele, Martín: Introducción a la teoría del Estado, Buenos Aires, Depalma, 1980, pp. 54-55. 
es relativa", porque en el Estado constitucional no desaparece la fuerza; precisamente, se espera que el Derecho construya la administración racional de la fuerza violenta que debe concentrar y monopolizar el Estado.

Para cumplir los objetivos planteados en este texto, he dispuesto una composición del discurso estructurada en tres secciones; así, en la sección 2, abrevo sobre el concepto de paz y su vínculo con el Derecho, mientras que en la sección 3 sugiero una comprensión del proceso de paz en el marco del Estado constitucional. Por último, en la sección 4 ofrezco comentarios conclusivos en el marco del Epílogo.

\section{§ 2. Sobre el concepto de paz y su vínculo con el derecho}

\subsection{Tesis básica}

Dos afirmaciones contundentes: el Derecho es una creación humana; la paz, también; ambos poseen entidad artefactual.

El Derecho es, básicamente, un sistema ${ }^{10}$ de reglas sobre la fuerza, que se materializa por el discurso de los poderes estatales y constituye el medio más idóneo para perseguir un objetivo mínimo: la paz relativa, dado que se relaciona con una comunidad determinada de hombres. La paz, en el contexto descrito, es el estado de cosas en el que por convicción y determinación no se hace uso de la violencia sin regulación centralizada y monopolizada. Así, la producción del orden descansa, aunque sea en nimia medida, en la participación de ciudadanos igualmente libres, que quedarán sometidos al propio orden generado. Una comunidad puede vivir en paz relativa, o sumergida en un pozo de guerra de todos contra todos o de algunos contra la mayoría, o viceversa. $\mathrm{O}$ los hombres eliminan la guerra (externa o

\footnotetext{
10 Bulygin, Eugenio: "Sobre el problema de la objetividad del Derecho", en AA.VV., Nancy Cardinaux, Laura Clérico y Aníbal D’Auria (coord.): Las razones de la producción del Derecho. Argumentación constitucional, argumentación parlamentaria y argumentación en la selección de jueces, Buenos Aires, Departamento de Publicaciones de la Facultad de Derecho, UBA, 2006, p. 40.
} 
interna), o la guerra que no cesa cancelará la vida humana en la Tierra ${ }^{11}$. En este último caso, sin ser agorero ni trágico, “... se necesitarían algunos millones de años para que los moluscos del mar llegaran a producir algo semejante al hombre"12. Ergo, el Derecho constituye una de las herramientas más específicas para intentar la resolución de las disputas.

\subsection{Debate mínimo}

Sucedió en tiempos inmemoriales y espacios finitos. Hubo un estado sin leyes sociales. En los principios de los tiempos y de los espacios en la Tierra, si el estado de naturaleza acaso existió y si acaso, como haya de ser comprobable que haya existido, fue un estado de cosas solamente gobernado por leyes naturales, que no fueron creadas por el hombre. Él puede dañarlas o mejorar algunos de sus efectos; pero nunca podrá una ley social regir la salida y puesta del sol, como tampoco podrá abolir o derogar la gravedad o la mecánica del calor y de la energía.

El Derecho procede directamente de la naturaleza humana. Significa el mayor invento para la ordenación de las comunidades humanas. En su interior, las constituciones son las tecnologías más desarrolladas que soportan toda la arquitectura del orden instituido jerárquicamente a través del escalonamiento gradual de enunciados normativos. El Derecho es un orden para la erradicación, eliminación o limitación máxima posible de la violencia como medio para afrontar los conflictos individuales o plurales

11 Born, Max; Bridgman, Percy W.; Einstein, Albert; Infeld, Leopold; Joliot-Curie, Frédéric; Muller, Hermann J.; Pauling, Linus; Powell, Cecil F.; Rotblat, Joseph; Russell, Bertrand y Yukawa, Hideki: Manifiesto Russell-Einstein: Una declaración sobre armas nucleares difundida a la prensa en Caxton Hall, Londres, 9 de julio de 1955: "Invitamos a este Congreso, y a través suyo a los científicos del mundo y al público en general, a suscribir la siguiente resolución: 'Ante el hecho de que en cualquier futura guerra mundial se emplearían con certeza armas nucleares, y que tales armas amenazan la continuidad de la humanidad, instamos a los gobiernos del mundo para que entiendan, y reconozcan públicamente, que sus propósitos no podrán lograrse mediante una guerra mundial, y les instamos, en consecuencia, a encontrar medios pacíficos que resuelvan todos los asuntos de disputa entre ellos'", disponible en http://www.filosofia.org/cod/c1955rus.htm, consultado el 1 de febrero de 2016.

12 Bobbio, Norberto: El problema de la guerra y las vías de la paz, Barcelona, Gedisa, 2008, p. 13. 
desatados en una comunidad de individuos. Al reglamentar el poder estatal y definir la libertad ciudadana, se puede erigir en un orden para conseguir la paz, una paz relativa. En pocas palabras, el Derecho, por un lado, es la sintaxis de la fuerza $\mathrm{y}$, por otro, se puede constituir en una apropiada semántica de la paz. Su morfología siempre es positiva, entendida como la cosa que es, el hecho de la autoridad existente y que nos ahorra pensar en arengas metafísicas. La tarea del jurista se centra en la descripción y sistematización del orden jurídico, aunque también no debería dejar de insinuar, con "prepotencia de trabajo"13, su crítica para la futura reforma, derogación o abolición del objeto estudiado.

El principal conflicto a resolver en una comunidad resulta en no dañar al otro, o en que nadie resulte dañado, o en que todos puedan tener la certeza de que no serán objeto de daño por parte del otro; este sujeto de la otredad puede llamarse "ciudadano" o "poder estatal". Se puede dañar al ciudadano porque se invade su esfera soberana de libertad o porque las autoridades creadas para el gobierno de la comunidad exceden o abusan de sus competencias férreamente regladas. Por eso, el único objetivo prioritario y mínimo que tiene el Derecho, su significado crucial, consiste en determinar, concertar y mantener la paz; no es la justicia ni el bienestar. Estos objetivos podrán ser posteriores, desde luego, pero el objetivo primordial del Derecho es la realización de la paz, porque sin paz es absolutamente imposible conseguir ninguna de las situaciones ideales en las cuales los seres humanos procuramos existir con dignidad ${ }^{14}$. La paz es el fin mínimo del ordenamiento jurídico ${ }^{15}$; esto implica

13 Arlt, Roberto: "Palabras del autor", a Los lanzallamas, Buenos Aires, Compañía General Fabril Editora, 1968.

14 Norberto Bobbio. El problema de la guerra..., ob. cit., pp. 96 a 97.

15 En 1872, R. Von Ihering, lo estableció en forma determinante: “...[L]a paz es el término del Derecho, la lucha es el medio para alcanzarlo". Rudolf von Ihering: La lucha por el Derecho, Librería General de Victoriano Suárez, Madrid, 1921, p. 2.

También merece recordarse el papel del Hans Kelsen. Así, en 1941 (The Law as a Specific Social Technique) renovó el anuncio de que: "[E]l Derecho es un orden que promueve la paz, 
encuadrarse en el pacifismo jurídico. La paz es la condición necesaria para cualquier otro fin: libertad, igualdad o fraternidad. El Derecho, entonces, es una procura de ordenación de la paz relativa de una comunidad.

La propiedad distintiva de un "propósito" lo constituye el objetivo que se pretende conseguir, el ánimo de alcanzar un determinado fin. La acción deliberada, mejor dicho, el propósito de crear y realizar el Derecho puede consistir en la arquitectura básica para la paz comunitaria. Como he planteado, esta posición se encuadra en el pacifismo jurídico, dado que la paz es el estado en que no se hace uso de la violencia desregulada. Sin embargo, no puede pasarse por alto la cuestión de que el Derecho no es un instrumento neutral, ya que siempre su normativa y aplicación vienen precedidas de presupuestos filosóficos e ideológicos. Suele argüirse que el Derecho es un instrumento para el control social; a la vez, se revela como la herramienta de la que se sirve racionalmente el hombre para intentar disponer la paz en el marco de la coexistencia comunitaria.

Con el Derecho se puede procurar una paz relativa, no absoluta, porque priva al individuo o grupo de individuos del empleo de la violencia. Para ello, se diseñan órganos y se les atribuye competencia para la ordenación de la vida en la comunidad estatal. Una "paz" que se pueda definir como la "inexistencia" de una relación de conflicto caracterizada por el ejercicio de una violencia duradera y organizada ${ }^{16}$. En este lenguaje, la paz es ausencia de conflicto armado. No obstante, sin minimizarlo, prefiero la reflexión sobre la "paz" en cuanto ella "evita el mayor

en el sentido de que prohíbe el uso de la fuerza en las relaciones entre los miembros de una comunidad". V. Kelsen, Hans: "El Derecho como técnica social específica", en la obra ¿Qué es Justicia?, Planeta, Buenos Aires, 1993, p. 160

Recientemente, E. Raúl Zaffaroni ha dicho: "[E]l Derecho siempre es lucha y es político y, si bien la paz no se gana con guerras, no es menos cierto que se gana con luchas, que no tienen por qué ser violentas, sino también jurídicas, como la denuncia, pues nuestra herramienta es el discurso, al que todas las dictaduras temen y por eso la reprimen". E. Raúl Zaffaroni: “El totalitarismo plutocrático corporativo", Página 12, edición del 12/8/2017, p. 40.

16 Ibíd., p. 164. 
de los males, la muerte violenta", y el bien al que aspira es el "bien de la vida"17, el mayor de los bienes. Por eso tiene tanta buena prensa, entre los estudios dogmáticos, apuntar a otro tipo de bienes: la justicia, el bienestar... Sin embargo, en realidad, la condición mínima reside en evitar este mal; se debe procurar su eliminación o al menos la ilusión de que podemos reducir a su máxima expresión la conflictividad armada, que trae consigo la muerte violenta y todo tipo de otros males y castigos depredadores o degradantes de la mismidad de la vida humana.

Una comunidad con leyes sociales es una sociedad que se orienta a la supervivencia y conservación del grupo social. En ese plan, se asigna a cada individuo un propio poder soberano, y se determina y delimita el poder de cada ciudadano con relación al poder propio de los demás. Nótese que una sociedad controlada íntegramente por el Derecho es un ideal inalcanzable, porque la observación y comprensión mundana de la realidad que se objetiva, sin prejuicios, lo contradice (en todos los tiempos).

En las letras que anteceden he aclarado que la paz procurada por el Derecho no es ausencia de fuerza; se constituye en el monopolio de la fuerza estatal, en favor de la comunidad por intermedio del Derecho. Una definición tomada de Luigi Ferrajoli describe el principio de la paz en estos términos: “... Si el uso de la fuerza no está disciplinado por normas jurídicas está prohibido. Y significa, por consiguiente, que el Derecho es la negación de la fuerza desregulada y que la fuerza desregulada es la negación del Derecho"18. Dentro de este plano maestro, la paz resulta ser la expectativa del uso no desregulado de la fuerza. La propuesta del Estado constitucional, por tanto, será instaurar leyes válidas y eficaces que hagan cesar el conflicto, regulen la fuerza, y que así nazca la paz. En definitiva, la paz no es ausencia de fuerza; se constituye en el monopolio de la fuerza estatal, en favor de la comunidad ${ }^{19}$.

\footnotetext{
17 Ibíd., p. 174.

18 Ferrajoli, Luigi: Principia iuris. Teoría del Derecho, Madrid, Trotta, 2011, T. I, p. 445.

19 Ibíd. y loc. cit.
} 
El principio de la paz, aun cuando expresa la expectativa negativa del no uso desregulado de la fuerza, inaugura con solidez el criterio de demarcación entre Derecho y "no Derecho", pero merece ser completado, según refiere Luigi Ferrajoli. En efecto, para definir finalmente el concepto de paz en su vinculación con el Derecho será menester evaluar y señalar: i) la existencia de una garantía primaria, esto es, la prohibición del uso desregulado de la fuerza, y ii) la existencia, paralela, de una garantía secundaria de necesaria e inmediata complementación con la primera; consistente, en este caso, en la limitación del uso de la fuerza en la forma y condiciones normativamente previstas, con exclusividad y positividad a los casos en que tal prohibición es violada ${ }^{20}$.

Ahora bien. Ligada la correspondencia entre "Derecho" y "paz", es momento de meditar sobre la constitución, pieza fundamental del Estado. La constitución es una categoría jurídica única en la existencia con vida de los seres humanos. Se trata de un instrumento que aún no tiene 250 años (si computamos desde la Constitución de Filadelfia, son 230 años), mientras que el Homo sapiens cuenta con 250.000 años. Los seres humanos nunca han conocido una invención similar a la constitución. Hasta lo conocido y creado por los seres humanos, las constituciones son el máximo instrumento de ordenación de la vida comunitaria.

La constitución, al fijar determinados procedimientos, cumpliría la función responsable de la más alta alcurnia atribuible a las formas jurídicas o al Derecho: alentar la paz. Sus principios se dirigen hacia un objetivo procesal, porque la siempre tensa relación entre ciudadanos y Estado nunca es susceptible de resolver por entero y, por eso, se la canaliza o reconduce a determinados actos que alivien la rigidez. La prosa del Derecho constitucional, su expresión objetiva puesta en el mundo (que muchos apodan "positiva"), pretende determinar marcos para colaborar con las ilusiones sobre la esperanza de una

20 Ferrajoli, Luigi: Principia iuris..., ob. cit., pp. 837 a 838. 
coexistencia pacífica en la que todos los ciudadanos disfruten o puedan disfrutar del casi inalcanzable "bienestar general", en una sociedad de ciudadanos iguales no sólo en libertad.

Sin Derecho constitucional -fluya de una ley fundamental escrita o que esta norma le confiera jerarquía suprema a instrumentos internacionales sobre derechos humanos dentro del propio orden jurídico estatal-, no hay Estado constitucional, porque aquél le confiere fundamento, en el arraigo o en la en la justificación o legitimación. ${ }^{21}$ Por eso, si todos los hombres vamos a coexistir con vida juntos, debemos aceptar las "letras sobre una tolerancia consistente y un respeto abnegado", instituidas por lo general en la constitución, que instruyen el mejor mecanismo para la paz, porque implican la terminante prohibición de dañar al otro y el categórico estímulo de ayudarlo siempre que se pueda. Estas proposiciones, por cierto, se enmarcan en un contexto utilitario, en el que también se prohíbe "derramar sangre" 22 o procurar que los procesos se orienten a que aquello no suceda. Así, se sustituye la lucha cuerpo a cuerpo por el debate cívico; en fin, se suprime “... el tiro de gracia del vencedor sobre el vencido por el voto y la voluntad de la mayoría que permite al vencido de ayer convertirse en el vencedor de mañana sine effusione sanguinis"23.

Cada constitución contiene y dispone una forma singular y peculiar de fundamentar al Estado ${ }^{24}$. Hay países que emplean poco más de 12.000 palabras para ordenar la totalidad de su código constitucional, como la Argentina. La Constitución de Paraguay

21 V. Ferreyra, Raúl Gustavo: "Manifiesto sobre el Estado constitucional. Reglas fundamentales sobre raigambre y justificación de la comunidad estatal", $1^{\text {a }}$ parte, Revista de Derecho Público, $n^{0}$ 10, Presidencia de la Nación, Ministerio de Justicia y Derechos Humanos, 2015, pp. 37-124 Y "Manifiesto sobre el Estado constitucional. Reglas fundamentales sobre raigambre y justificación de la comunidad estatal", $2^{a}$ parte, Revista de Derecho Público, n 11 , Presidencia de la Nación, Ministerio de Justicia y Derechos Humanos, 2015, pp. 109-182.

22 Popper. Karl: La responsabilidad de vivir: escritos sobre política, historia y conocimiento, Barcelona, Paidós, 1995, p. 190.

23 Bobbio, Norberto: El problema de la guerra..., ob. cit., p. 19.

24 Ferreyra, Raúl Gustavo: Fundamentos constitucionales, Buenos Aires, Ediar, 2015, pp. 344 y ss. 
de 1992 emplea más de 25.000 palabras. Otros ejemplos, como Ecuador, necesitan más de 54.000 palabras. Brasil requiere la utilización de más de 76.000 palabras. Colombia ha prescrito su ordenación fundamental del Estado mediante el empleo de más de 40.000 palabras. En consecuencia, cada comunidad posee un modelo propio y peculiar para transitar el camino al paradigma constituyente y, así, fundamentar al Estado.

Los "libros laicos"25, es decir nuestras constituciones, como se dice, contienen diferentes modalidades para ordenar. Empero, la paz no puede insertarse con inocencia, porque es un acto informado de todo hombre que posee cabal conciencia de sus derechos. En la siguiente sección doy cuenta de un modelo teórico, cuya abstracción autoriza una aproximación a la fundamentación constitucional del Estado en directa implicación con la paz. Repito que se trata de una construcción centrada en la ciudadanía, en la inherente e irrepetible individualidad de cada ciudadano.

\subsection{Con forma de inventario}

(i) La vinculación entre paz y Derecho es fértil, indispensable y necesaria.

(ii) La paz es la condición necesaria para cualquier otro fin: libertad, igualdad o fraternidad. El Derecho no puede ser otra cosa o estados de cosas, entonces, que la orientación hacia la paz ordenada de una comunidad estatal.

(iii) Los mandamientos del Derecho son elementales, pero el Derecho no tiene aptitud para contener o detener una guerra o conflicto con nombre semejante. La política hace al Derecho, motivo por el cual la decisión máxima es, al mismo tiempo, un esbozo de salvación. Se debe ejercer una

\footnotetext{
25 Arriba, en el cuerpo principal, se desarrolla la afinada acuñación semántica anticipada por Valadés, Diego: “¿Qué hacer con la Constitución?", en Reforma, México, 2 de febrero de 2016, disponible en www.reforma.com/aplicacioneslibre/editoriales/editorial.aspx?id=8122 0\&md5=05567a7fe830663d1a4b14d63064c495\&ta=0dfdbac11765226904c16cb9ad1b2efe\& Icmd5=2ebc84d163eeaf4cb937892081ba9526, consultado el 17/7/2017.
} 
rebelión cotidiana y ecuménica contra la guerra: la rebeldía humana se expresa con "un hombre que dice $n o^{\text {"26; }}$; en este caso, "no a la guerra". Hay que detenerla.

(iv) Negarse a la guerra, repudiarla con energía y sin desmayo, significa abrir la existencia de la paz. ${ }^{27}$

(v) El Estado constitucional es un estado con leyes sociales. Estas últimas, por intermedio del paradigma "constitución", confieren su ordenación y fundamento básico. El Estado constitucional, fundado en una ley fundamental, puede prescribir, apropiadamente, los procesos para alcanzar, afianzar y desarrollar la paz comunitaria.

\section{§ 3. Fundamentación constitucional del Estado}

\subsection{Afirmación capital}

Todo "Estado constitucional" ${ }^{28}$ se integra con 4 elementos: dos naturales (territorio y población) y dos no naturales (poder y constitución). En el Estado constitucional todo su Derecho debe ser Derecho autorizado y/o validado por la norma fundamental de su orden coercitivo puesta en el mundo por el poder constituyente que se debe ejercer, siempre, en representación de la ciudadanía; caso contrario, si no fuese ejercido en el escenario antedicho -la representatividad de la ciudadanía-, no se trataría de un orden que ejerciese cohesión y unidad en la comunidad, dado que se fundaría en una pura autocracia sin representación.

\footnotetext{
26 V. Camus, Albert: L'Homme révolté, Paris, Euvres, Gallimard, 2013, p. 854.

27 La Costituzione della Repubblica Italiana de 1947 contiene una preciosa regla sobre la materia. Se ordena en el artículo 11: L'Italia ripudia la guerra come strumento di offesa alla libertà degli altri popoli e come mezzo di risoluzione delle controversie internazionali; consente, in condizioni di parità con gli altri Stati, alle limitazioni di sovranità necessarie ad un ordinamento che assicuri la pace e la giustizia fra le Nazioni; promuove e favorisce le organizzazioni internazionali rivolte a tale scopo. Sobre el particular se puede leer, Celotto, Alfonso: Costituzione Ragionata, Roma, Nel Diritto Editore, 2016, p. 11-12.
}

28 Bonavides, Paulo: Curso de Direito constitucional, 26 ed., São Paulo, Malheiro Editores. 


\subsection{La constitución, cuarto elemento del Estado}

Con tales precisiones, conviene considerar con firmeza que la constitución no es un ente perdido o que se le pueda desgajar para su conocimiento científico. Eventualmente, se le puede recluir para beneficiar un estudio dogmático y describir su propiedades inherentes; se trata, pues, de una "comprensión interna". Empero, paralelamente, se puede completar una "comprensión externa": la modalidad concreta que asume el ente constitucional, el artificio o artefacto, para fundamentar al Estado.

\subsection{Las reglas constitucionales}

Teóricamente, desde dicha comprensión externa, el Estado podría quedar fundado por apelación a cuatro principios o reglas: subordinación, variación, distinción y acción. Ninguna de estas reglas o principios posee una realización absoluta; por eso son reglas "inacabadas" o reglas de realización progresiva, o reglas de realización relativa. ${ }^{29}$

Los cuatro principios o reglas que surgen de la constitución reconocen una elaboración o factura inacabada, pero siempre por su regia vía se intentará fundamentar la regulación del Estado y/o la limitación de su poder.

\subsubsection{Regla sobre la subordinación}

La regla sobre la subordinación jurídica del Estado por intermedio de cada uno de los despliegues que la constitución dispone (supremacía normativa; relación con el Derecho internacional de los Derechos Humanos -DIDH-; control de

\footnotetext{
29 No asumo la distinción fuerte y débil, respectivamente, entre principios y reglas. Nótese: no significa que la distinción no posea entero fundamento; simplemente, es preciso señalar que tiene un alcance y contenido explicativo bastante más reducido del que comúnmente se le asocia, dado que la mayor parte de los principios, tendencialmente, se comportan como las reglas, porque también son "Derecho sobre Derecho", portadores de sana normatividad. Sigo, en general, la consistente tesis de Luigi Ferrajoli, expuesta en "Constitucionalismo principialista y constitucionalismo garantista", en Un debate sobre el constitucionalismo, Madrid, Marcial Pons, 2012, pp. 11-50.
} 
constitucionalidad y rigurosa juridicidad) persigue establecer la certeza, es decir, el "conocimiento seguro" por parte de la ciudadanía y los servidores públicos sobre la determinación del campo dominado por el Derecho y del otro campo libre, un mundo sin reglas jurídicas. Los ciudadanos y los servidores públicos deben realizar el Derecho de la constitución.

Con los alcances de sus prescripciones jurídicas, inevitablemente, hacen presuponer o representar que la certeza en el mundo estatal -pasado, presente y sobre todo porvenir- queda afianzada, se encuentra ligada, en fin, subordinada a una regla artificial: la constitución, que no tiene nada de orden metafísico. La certeza siempre es "... certeza de alguien respecto de algo" ${ }^{30}$; en nuestro caso, nada más y nada menos que del hombre sobre el orden jurídico que fundamenta al Estado.

Gracias al empleo de la regla sobre la subordinación y sus despliegues, toda la vida comunitaria -la ciudadana en libertad y las tareas de los servidores públicos- debería quedar dominada por la ordenación constitucional. Aunque la certeza que puede alumbrar la normatividad constitucional no alcanza a constituir por sí misma y en su integridad todo un proceso de paz social, la previsibilidad congénita que arraiga la propia subordinación que establece la constitución para el resto del orden jurídico, sin dudas, favorece a su instauración y a su mantenimiento.

\subsubsection{Regla sobre la variación}

La constitución contiene una certidumbre: que su escritura metódica sólo podrá ser expandida, contraída o revisada, por el propio proceso detallado en su texto. Autoriza un solo lenguaje posible, por intermedio de un modelo autorreferente. El propio proceso de su cambio formaliza, sin temores, que la constitución puede ser reformada, con el debido respeto de sus determinaciones precisas, que nunca pueden ser entendidas como epístolas inútiles. De este modo, el artificio constitucional

30 Bunge, Mario: Diccionario de Filosofía, "Certeza", México, D.F., Siglo Veintiuno, 2001, pp. 213-214. 
arraiga y afianza la estructura del Estado, al permitir el cambio de la regla suprema, que no es la copia ni imitación de ningún ente u objeto perfecto e ideal. Por eso corresponde habilitar la propia metamorfosis de la constitución.

Fuera de la canalización dispuesta en la constitución, no hay cambio autorizado. La autoridad creada por la constitución no debe disponer cambios fuera del proceso político y jurídico prescrito en la suma regla. El cambio es una posibilidad enorme en la vida de los hombres. Arraigar, entonces, el cambio constitucional a un proceso clave e indisponible consagrado, en modo autorreferente, también confiere certeza en las relaciones humanas.

Las bases que surgen de las previsiones sobre reforma constitucional no eliminan la irracionalidad. Sí confieren certidumbre a la variación normativa. Cambiar, con arreglo a reglas predispuestas, disuelve la ley del más fuerte o la fuerza bruta, que, conjunta o separadamente, desalientan cualquier proceso de paz por la violencia congénita y sin regulación que portan y transmiten.

\subsubsection{Regla sobre la distinción de funciones}

Para construir y mantener jurídicamente a esa personalidad colectiva que se apoda "Estado", inevitablemente, unos hombres tendrán que dar órdenes, encontrarse facultados para mandar con atribuciones suficientes, y otros deberán obedecerlas, ya sea por leal convicción, o por otro motivo que influya y determine el estado de dominación.

El poder se distingue en "constituyente" y "constituidos": Derecho constituyente y Derecho constituido. La constitución es producida y concretada en los "momentos constituyentes"; el resto de las reglas jurídicas de alcance general son creadas por el Congreso federal o el departamento ejecutivo; excepcionalmente, por el poder judicial.

En el seno de la constitución, la división horizontal del poder tiene lugar en la casa republicana: departamentos precisos, con 
atribuciones excluyentes y bien determinadas, que se encargan de la producción o realización del Derecho.

La división vertical del poder tiene lugar ya sea por la vía del federalismo o del unitarismo; Brasil y la Argentina, por ejemplo, son modelos federales. Colombia, Paraguay y Ecuador instituyen modelos unitarios.

La división del poder, en el Estado constitucional, constituye la regla organizativa fundamental. $\mathrm{Al}$ mismo tiempo, se ha observado que si la premisa antropológica es la "dignidad humana"31, su consecuencia organizativa debe ser la democracia. Desde que no existe democracia sin división del poder, entonces, la vinculación es evidente. En los términos postulados, la regla sobre la división del poder justifica la existencia del Estado constitucional. Sin embargo, dividir el poder, desconcentrar las funciones y diseñar controles no asegura un proceso de paz. Por ello, la regla sobre la distinción de funciones y la correlativa generación de controles entre órganos -concretamente, una "gramática" del poder estatal- tiene por inocultable finalidad contribuir a la consecución de lo que cotidianamente parece imposible, o digno de una de las más fantásticas de las utopías: someter el poder al cumplimiento de reglas de juego jurídicas preestablecidas y, con ello, a una expectativa de concentración, regulación y administración de la violencia. Dentro del marco propiciado por la regla de distinción, se genera la ilusión de que no debería existir fuerza desregulada; empero, todos saben que allí donde existe un poder puede existir, también, un servidor dispuesto a ejercer una fuerza estatal no disciplinada por normas jurídicas. Así, la paz cuenta más como una utopía. Porque, allí donde existe un poder constituido, usualmente, existe un servidor público bien decidido a su abuso y corrupción, ya sea por la violación del orden de cosas constitucionales instituido o por apelación al estado de excepción o emergencia.

31 Häberle, Peter: El Estado constitucional, México, D.F., UNAM, Instituto de Investigaciones Jurídicas, 2003, p. 193. 


\subsubsection{Regla sobre la acción. Derechos fundamentales}

Las constituciones pretenden sostener y conferir validez a los órdenes jurídicos que se generan a partir de ellas. Todas las constituciones tienen un legajo importante o inmenso de derechos fundamentales a los que se les confiere reconocimiento. Los derechos fundamentales insertados en las constituciones son líneas significativas para la acción estatal y ciudadana. Así, al trazar las líneas de acción respectivas, una paz interna comunitaria fundada en el desarrollo de los derechos fundamentales puede significar la negación de la violencia sin regulación ni disciplina en una comunidad organizada. ${ }^{32}$

Concebir de este modo a los derechos fundamentales significa que ellos son derechos subjetivos; empero, también, normas objetivas del orden que disciplinan y sostienen. La comprensión objetiva de los derechos fundamentales los emplaza, objetivamente, como líneas de acción que deben asegurar un uso correcto de la fuerza estatal para la consecución, mantenimiento y desarrollo de una coexistencia comunitaria en paz.

Veamos una descripción jurídica. La Constitución de la Argentina reglamenta los derechos fundamentales, básicamente, en: (a) su Primera Parte, Capítulo Primero: "Declaraciones, derechos y garantías"; Capítulo Segundo: "Nuevos Derechos y Garantías"; y (b) su Segunda Parte, Título Primero, Sección Primera, Capítulo Cuarto: "Atribuciones del Congreso", art. 75, inc. $22^{33}$ ). Sin lugar a dudas, la nomenclatura constitucional

32 Las tesis sobre los derechos fundamentales como directivas básicas del orden jurídico fue adelantada y desarrollada por el autor. V. Ferreyra, Raúl Gustavo: Enfoque sobre el mundo jurídico. Constitución y Derechos Fundamentales", en Academia. Revista sobre enseñanza del Derecho, año 11, n² 21, Academia. pp. 243-282. Buenos Aires, Facultad de Derecho, Buenos Aires, 2013.

33 Por intermedio de la reforma constitucional de 1994 se dispuso en el art. 75, inc. 22: “... Corresponde al Congreso (...) inciso 22: Aprobar o desechar tratados concluidos con las demás naciones y con las organizaciones internacionales y los concordatos con la Santa Sede. Los tratados y concordatos tienen jerarquía superior a las leyes. La Declaración Americana de los Derechos y Deberes del Hombre; la Declaración Universal de Derechos Humanos; la Convención Americana sobre Derechos Humanos; el Pacto Internacional de 
citada, constituye la directiva fundamental para que los poderes constituidos, en ejercicio de sus tareas inherentes, determinadas y específicas, pueden lograr el afianzamiento de la paz social.

\subsection{Con forma de inventario}

(i) Los animales se encuentran en el mundo; probablemente sean "felices mientras tengan salud y suficiente comida" ${ }^{4}$. El hombre, en forma bien diferenciada y distinguida de aquéllos, pretende la comprensión y segura observación mundana. El hombre, con la guía de su razón siempre imperfecta y el respaldo en su experiencia siempre susceptible de verificación, intenta ejercer y desarrollar cierto tipo de dominio sobre el mundo para que éste sea, quizá, más acogedor y también objeto de transformación. La naturaleza, en suma, configura un mundo dado o presentado al

Derechos Económicos, Sociales y Culturales; el Pacto Internacional de Derechos Civiles y Políticos y su Protocolo Facultativo; la Convención sobre la Prevención y la Sanción del Delito de Genocidio; la Convención Internacional sobre la Eliminación de todas las Formas de Discriminación Racial; la Convención sobre la Eliminación de todas las Formas de Discriminación contra la Mujer; la Convención contra la Tortura y otros Tratos o Penas Crueles, Inhumanos o Degradantes; la Convención sobre los Derechos del Niño; en las condiciones de su vigencia, tienen jerarquía constitucional, no derogan artículo alguno de la primera parte de esta Constitución y deben entenderse complementarios de los derechos y garantías por ella reconocidos. Sólo podrán ser denunciados, en su caso, por el Poder Ejecutivo nacional, previa aprobación de las dos terceras partes de la totalidad de los miembros de cada Cámara. Los demás tratados y convenciones sobre derechos humanos, luego de ser aprobados por el Congreso, requerirán del voto de las dos terceras partes de la totalidad de los miembros de cada Cámara para gozar de la jerarquía constitucional". A su vez, la ley 24.820 -publicada en el B0 del 29/5/1997- otorgó jerarquía constitucional a la Convención Interamericana sobre Desaparición Forzada de Personas, aprobada por la XXIV Asamblea General de la OEA, en los términos del art. 75, inc. 22, de la Constitución federal. Por su parte, la ley 25778, publicada en el B0 el 3/9/2003, otorgó jerarquía constitucional a la Convención sobre la Imprescriptibilidad de los Crímenes de Guerra y de los Crímenes de Lesa Humanidad, adoptada por la Asamblea General de la ONU el 26/11/1998 y aprobada por ley 24.584. Por su parte, la ley 27.044 publicada en el $\mathrm{BO}$ del 22/12/2014 dispuso otorgar jerarquía constitucional en los términos del art. 75, inc. 22 de la Constitución Nacional, a la Convención sobre los Derechos de las Personas con Discapacidad (ONU). En consecuencia, hoy son 14 los instrumentos del Derecho Internacional de los Derechos Humanos que gozan de jerarquía constitucional.

34 Russell, Bertrand: La conquista de la felicidad, Barcelona, De Bolsillo, 2003, p. 21. 
hombre; éste, con sus invenciones y descubrimientos científicos, artísticos, intelectuales o tecnológicos trata o intenta, en general, de mejorar las condiciones iniciales al construir otros "mundos artificiales" 35 . El Estado, el Derecho y la constitución son entes artificiales; también, naturalmente, la asociación que da lugar a la mancomunidad: "Estado constitucional".

(ii) Cada Estado tiene una historia detrás y cada historia estadual es única. Para la existencia de la vida de los hombres una forma de ordenación es absolutamente necesaria para el control responsable de la paz, aunque esa forma no imponga necesariamente un Estado.

(iii) El artificio constitucional constituye el cuarto elemento del Estado. Se ilustra un enfoque original: la conexión de la constitución con el ente que fundamenta, el Estado. Significativamente, el Derecho que emana de la constitución, o cuya validación ella con la más alta jerarquía promueve y protege, comprende el cuarto elemento, definido o caracterizado como fundamental del Derecho del Estado.

(iv) En el Estado ordenado con fundamentos en una constitución, su constitucionalización nunca es cabal ni totalizadora. Las reglas constitucionales que fundamentan al mencionado Estado prescriben con bastante suficiencia: la subordinación certera de su orden jurídico, la autorización detallada para su cambio formalizado, la distinción de las funciones controladas de sus poderes gubernativos $\mathbf{y}$ notable literatura sobre la acción de sus derechos fundamentales. Tales reglas constitucionales, al fijar determinados procedimientos singulares, cumplirían la función responsable de la más alta alcurnia, atribuible a los procesos jurídicos: alentar la paz. Precisamente, en principio en el Estado constitucional, la constitución cumple un rol eminentemente procesal, porque la tensión entre individuo y Estado, el conflicto entre ciudadano y autoridad, imposible

Bunge, Mario: La ciencia. Su método y su filosofía, Buenos Aires, Siglo Veinte, 1977, p. 9. 
de resolver con rasgos definitivos, se disuelve a favor de determinados procedimientos que subordinan la actuación estatal al Derecho de la constitución.

(v) En las letras anteriores no persigo un tipo ideal de estado constitucional. Sólo guardo la expectativa de que la descripción del "modelo normativo determinado" pueda ser objeto ulterior de una ampliación y tipificación, por ejemplo, en América del Sud.

\section{§ 4. Epílogo}

Primero. Suele creerse que la lengua del Derecho constitucional alcanza una condensación más elevada o será mejor identificada por las ordenaciones que se prescriben en su "expreso y propio decir (lo que explícitamente ordenan), que por el mundo que espacialmente se encuentra fuera de ellas, que queda sin el gobierno de las prescripciones de su fluir lexical; esto es, sin dicción constituyente, el mundo no jurídico. Por mi parte, sostengo la lengua del Derecho constitucional puede ser un código para la paz. Su texto o escritura es la literatura seglar ${ }^{36}$ de los ciudadanos que integran el pueblo de la comunidad estatal. La lengua escrita del Derecho constitucional es fundamental: marca precisamente el ámbito de actuación de los ciudadanos y servidores públicos. La referencia del Derecho constituyente del Estado se encuentra allí: dentro de los 4 márgenes que contienen las letras constitucionales. La lengua prescriptiva de la constitución no es una flor a disposición semántica del servidor público. El único fruto jugoso y robusto del Derecho constitucional surge, en el preciso momento, en

\footnotetext{
36 Los enunciados normativos siempre conducen al ciudadano o servidor público a un sitio de mayor reverencia o menor "religiosidad". La Constitución de Francia de 1958, en su art. 1, define con sobriedad y rotundidad eminente la tajante separación entre "la Iglesia y o cualquier culto religioso" y el Estado constitucional": "La France est une République indivisible, laïque, démocratique et sociale". Resulta innecesario mencionar mi elección por esta fórmula normativa tan preciosa. He aprendido que "los estados de cosas vitales" deben ser pronunciados al comienzo de cualquier discurso; en tales condiciones, pues, a la laicidad del Estado, la cabecera, le corresponde por derecho propio.
} 
que con voces propias, ciudadanos y servidores cumplen y realizan sus órdenes. Pensar que el lenguaje para la ordenación comunitaria no se encuentra, en esencia, en la constitución, significa colocar a la ciudadanía colgada del barranco de polvo y piedra que maneja la autoridad despótica y arbitraria.

Segundo. El Derecho constitucional fundamenta al Estado y debe cumplir un servicio supremo: con sus procesos formales, debe articular y mantener el constituyente supremo de la paz. Porque sin paz no habrá ni libertad ni justicia.

Tercero. Hay palabras con las que nadie desea quedar nunca ligado, por ejemplo, "guerra", "terror", "racismo", "muerte", "contaminación". Sin embargo, hay otras que generan el deseo de que todas las personas se encuentren inclinadas a discurrir sobre ellas: "tolerancia", "maternidad", "protección ambiental" y, por supuesto, "paz". Con excepción de algunas teocracias islámicas o algunos jeques asiáticos, resulta imposible encontrar un sistema de ordenación estatal que no pregone, no programe, no estimule o de cualquier forma rinda pleitesía y tributo a la paz; aunque ello, desgraciadamente, en la vida cotidiana no suceda. Sin embargo, debe admitirse, que, en paralelo, hay Estados que pregonan la paz pero declaran la guerra e invaden países nuevos cada año; justamente, buscan reforzar su propio poder imperial y maximizar la concentración de la riqueza de bienes yacentes o a crearse, aunque pregonen otra cosa y quieran hacer creer que se encuentran en posesión de la razón absoluta, cuando en realidad con sus ideas y máquinas desarrollan una ideología bélica y asesina.

Cuarto. Reproduzco una cita que siento irresistible, perteneciente a Aleksandr Herzen: "con la violencia y con el terror se difunden religiones y políticas, se fundan imperios autocráticos y repúblicas inescindibles, con la violencia se puede destruir y despejar el lugar, nada más" ${ }^{37}$. Obviamente: me refiero a una violencia sin legitimación ni regulación, tal como se esboza más arriba en la sección §2; concretamente: el "No Derecho". Por

37 Herzen, Aleksandr L.: A un vecchio compagno, Turín, V. Strada (ed.), Eunadi, 1977, p. 6. 
eso, corresponde aquí insistir: el Derecho es instrumento para instituir y conservar un determinado orden del Estado. Fuera de la fundación o desarrollo del Derecho en la regulación del orden estatal, solamente, queda una esfera sin Derecho, puramente la anarquía de la violencia sin domesticación.

Quinto. La violencia sin regulación ni administración se acerca más y más a una suerte de "sepulturera de la historia"38. La paz es una conquista; por lo cual, una vez conquistada, habrá que desarrollarla y mantenerla, porque se la puede perder nuevamente.

Sexto. Erasmo de Róterdam, uno de los "pensadores mayores" en toda la historia de la humanidad, creyó que la paz se encontraba en la naturaleza. Asustado por el flagelo de la guerra, escribió probablemente hace casi 500 años un encomio con cita de Silio Itálico: "Paz, la mejor de las cosas que la naturaleza dio al hombre"39. Juzgo que es una lástima imperecedera que la concordia no se encuentre en la naturaleza o en la condición natural del hombre como propuso Erasmo, dado que la naturaleza de la paz es artefactual, un objeto de creación totalmente humana. Eso sí: estoy convencido y comparto con el genio humanista citado de que es el mejor de todos los estados de cosas en el que puede desarrollarse la existencia vital de los hombres.

Si maldito ha de ser el que sea que haya inventado la guerra $^{40}$, sin postular ninguna moral objetiva, deberían ser "benditos" quienes procuren su ausencia o su finalización. El Homo sapiens, como especie animal, tiene una edad aproximada de 2.500 siglos, aunque los cimientos de sus progresos en los últimos cinco han sido posiblemente muy superiores que

\footnotetext{
38 Bobbio, Norberto: El problema de la guerra..., ob. cit., p. 20.

39 V. Erasmo de Róterdam: "Querella de la paz. De cualesquiera pueblos echada y derrotada", en Obras escogidas, Buenos Aires, Aguilar, 1964, p. 972.

40 Marlowe, Christopher: Tamburlaine the Great, Part. I, Act II, Scene IV, "Accurs'd be he that first invented war", disponible en http://www.gutenberg.org/files/1094/1094-h/1094-h. htm\#link2H_4_0010, consultado el 18/7/2017.
} 
durante los 2.495 anteriores. El desarrollo, perfeccionamiento y expansión de la escritura ha sido fenomenal para depositar y transmitir conocimientos. Pese a ello, sigue vigente el problema inflexible y espantoso: " $¿ H e m o s$ de poner fin a la raza humana, o debe la humanidad renunciar a la guerra?"¹ . No hay oposición más radical e inspirada; la continuidad de la vida del hombre podría alentar un mejoramiento de las condiciones sobre su frágil existencia, porque su opuesto -el conflicto armado-, por conocido, no deja de contener nuestra rebelión hacia sus estremecedores resultados: cadáveres, violaciones, torturas, desplazamientos, pobreza y exclusión.

Séptimo. Antes de la caída del telón para este ensayo deseo recordar otra vez a nuestro humanista: "Solamente al animal humano fuele dada la palabra, principal conciliadora de amistades" ${ }^{42}$. Cuánta afinidad con los propósitos de este texto en el que la escritura intenta fundirse con el análisis jurídico. No hay nada subrepticio en este escrito. Apenas palabras que intentan ordenarse hacia la paz $^{43}$. La paz de una República, con sus ciudadanos entregados a la benevolencia mutua y a la concordia emergente de los significados racionales de sus palabras.

Octavo. Pretendería que mis palabras, a falta de cualquier otra consideración, fuesen interpretadas bajo el sello de una sola posesión e intransigencia: sublevación total, insubordinación completa, desobediencia absoluta y rebelión terminante contra la guerra o cualquier conflicto armado o semejante, interno o externo, que cancele la vida humana, como lo hizo y lo hace el

\footnotetext{
41 V. Russell, Bertrand; Einstein, Albert et al.: Manifiesto Russell-Einstein..., ob. cit.

42 Erasmo de Róterdam. "Querella de la paz. De cualesquiera pueblos echada y derrotada", ob. cit., p. 968.

43 La lengua puede ser herramienta para la paz; empero, el poder de la lengua, también, se puede emplear para la guerra. De hecho, lamentablemente, la última conjetura la realidad la confirma todos los días. La existencia humana es breve, finito, siempre perecedera por la misma materialidad del nacimiento del hombre. Las preguntas sobre la naturaleza del tiempo nos sobrecogen ante la maldición de la guerra. El tiempo constituye la estancia intermedia entre la inescrutable inexistencia de la nada y la desgarradora incerteza e inhospitalidad de la eternidad; por tanto, la guerra desarrollada en el tiempo de la existencia determina al hombre frente a la crueldad que le deparará la nada.
} 
encuentro violento, la beligerancia armada entre los hombres. Por todo ello, este texto puede ser acusado de parcialidad, ya que mi rebeldía contra la guerra no tiene cura ni conciliación racional.

Noveno. Todos los objetos tecnológicos inventados por el hombre poseen un "manual de usuario". La constitución del Estado resulta también un objeto tecnológico que, sin embargo, no contiene un manual de uso, porque ella misma es el "manual del ciudadano" para el desarrollo y mantenimiento de un constitucionalismo en procura de paz.

El Estado constitucional, quizá, signifique una ideación infinitamente más potente que su apropiada concreción en la realidad política comunitaria. Sin embargo, para vivirlo a pleno hace falta, entre otras actividades, la pura pedagogía constitucional. Hace años se ha dicho que una "constitución no hace en absoluto a un Estado, salvo en la más estricta significación literal, un auténtico Estado constitucional" ${ }^{44}$. En ninguna de las líneas anteriores apelé al juego de palabras, porque juzgo relevante la cruda descripción, sin la complaciente veneración en que incurren ciertos intérpretes que creen posible un inexistente culto oficial a la constitución, olvidando la más genuina posibilidad entregada por la "sociedad abierta" ${ }^{45}$ : o todos realizamos el Derecho constitucional, o el Derecho constitucional es simplemente una nueva forma arbitraria e irracional de dominación. Tampoco ahora jugaré con las palabras. Bastará, por eso, una afirmación, con igual pureza teórica que la perseguida en la sección 2: sin constitución, no hay Estado constitucional, porque las cuatro reglas aquí reportadas fomentan la ilusión de que los ciudadanos sean efectivamente iguales en libertad y el poder constituido constituya una zona de competencias limitadas sometidas al control racional.

\footnotetext{
44 Loewenstein, Karl: Teoría de la constitución, Ariel, Barcelona, 1979, p. 161.

45 Häberle, Peter: "La sociedad abierta de los intérpretes constitucionales: una contribución para la interpretación pluralista y 'procesal' de la Constitución", en Academia. Revista sobre enseñanza del Derecho, año 6, n 11, Departamento de Publicaciones de la Facultad de Derecho de la Universidad de Buenos Aires, 2008, pp. 29-61.
} 
El Estado constitucional representa a la comunidad política soberana. Él mismo es un ente autorreferente. La regulación, administración y planificación de la fuerza del ente estatal se realiza por intermedio de un orden jurídico, que desde su primacía muestra una constitución, instrumento que debería contener la decisión formalizada, incontestable y unida de los ciudadanos que integran el pueblo. La constitución, por tanto, define un sistema de poder excluyente para toda la comunidad. Una ordenación que resuelve, jurídicamente, la validez de la totalidad de las normas que se le subordinan y que nacen en la fuente estatal. A su vez, el orden constitucional también decide la autorización para la aplicación eventual de las normas que provienen de fuente extranjera y, por ende, se las emplace en la cúspide del sistema estatal. La apuesta por este tipo o modelo de orden constituyente del Estado implica, además, la negación de cualquier otro orden que pretenda afectar su supremacía lógica, que siempre existirá en la realidad política, porque se trata de una trama insuperable. En suma, el proceso de disciplina, regulación y aplicación de la violencia, en este tipo de Estado, se decide, básicamente, por el instrumento constitucional. Con la configuración de este poder constitucional, el presupuesto primero de la comunidad política, la paz, lograría un criterio de razonable efectividad, a condición de que los ciudadanos participen activamente en el nacimiento, en el desarrollo y en la profundización de tal constitucionalismo.

Décimo. La conservación de la existencia de la vida humana configura la idea principal que desarrollo en estas escrituras. Para ello, la eliminación radical de la guerra constituye "nuestro problema supremo" ${ }^{46}$. No existe ninguna otra idea que tenga mayor supremacía a la expuesta. Por de pronto, aquí, no se concentran soluciones. Sí, juiciosamente, directivas básicas para la edificación de la vida comunitaria en paz. Dentro de ese panorama, todas las constituciones de cada uno de los Estados de América del Sud poseen piezas muy interesantes para la

46 V. Kelsen, Hans: La paz por medio del Derecho, Buenos Aires, Losada, 1946, p. 47. 
construcción duradera y estable de una paz relativa en cada comunidad.

Nótese que se ha sobrestimado respecto de la utilidad de nuestras constituciones. Ellas, con sus textos genuinos, no deberían contener ni presuponer ningún acto de magia; al contrario, por lo general, sus prescripciones deben elaborarse y enfrentar, dado que los sudamericanos no estamos solos en el mundo, a poderes hegemónicos, salvajes y planetarios, portadores de perturbadoras ideas neocoloniales ${ }^{47}$ que solamente pretenden más dominación y más injusticia. Nuestras constituciones deberían quedar enteramente libres del mito y la metáfora. También, por supuesto, de la plegaria y de la magia. Así, quedaría más libre el camino para la discusión racional y el diálogo, aunque, desde luego, el pesimismo debería aumentar si se ha de conjurar a la hegemonía del neocolonialismo.

El mejor modo para preparar el presente e iluminar un porvenir reside en disponer de la lucidez suficiente para actuar con energía y reunir, definitivamente, la idea ciudadana de que las constituciones, en principio, son "manuales para una procura de paz relativa comunitaria”. Ciertamente, la vida política de cualquier comunidad se desenvolverá, siempre, sobre un imaginario de conflictos ciudadanos, cuya totalidad jamás serán resueltos por completo. Quizá, entonces, pueda parecer poco ambicioso postular un "constitucionalismo ciudadano" que simplemente procure una paz relativa. Por amor a la verdad, pienso que es una condición necesaria para la existencia de la vida humana con dignidad. La necesidad, pues, de este tipo de "constitucionalismo ciudadano" nos permite ilusionar en procedimientos para evitar y regular los conflictos. Puede ser criticado, con rigor, porque no enfrenta con decisión a la desigualdad, cuya persistencia o aumento corroerá las mínimas bases de la paz social. Pero no podrá decirse sobre él que no autorice a que cada ciudadano es cuanto individualidad insobornable, cuya

\footnotetext{
47 V. Zaffaroni, E. Raúl: El Derecho latinoamericano en la fase superior del colonialismo, Buenos Aires, Madres de Plaza de Mayo, 2015, pp. 24-25.
} 
presencia erguida y sin encoger ilumina la medida de todas las cosas que son y de las cosas que serán; me refiero, concretamente, a los estados de cosas constitucionales que presuponen la paz. Ciudadanos que decidan a la luz del día, condición básica para llevar su propia existencia en paz. ${ }^{48}$

La paz comunitaria es el resultado de la sujeción de los ciudadanos a la fuerza regulada e irresistible, encerrada y dispuesta por el orden instaurado por el artificio constitucional. No hay nada natural en esto, porque es todo es obra de un artefacto, la constitución. Sin embargo, constituye un segundo paso del constitucionalismo ciudadano la escandalosa, escalofriante, perversa e inhumana desigualdad que afecta a los ciudadanos de la abrumadora mayoría de los Estados sudamericanos, respecto de la riqueza y los bienes (yacentes y creados), la cual privilegia con injusticia a una notable, reducida y escogida minoría ${ }^{49}$.

48 La tesis sobre la igualdad fue desarrollada y fundada por el autor. V. “Gobernar es igualar. Isonomía, igualdad de oportunidades y justicia social en la Argentina". Academia. Revista sobre enseñanza del Derecho, año 14, número 28, 2016, pp. 185-227. Buenos Aires, Argentina. Este ensayo sobre la paz comunitaria, ciertamente, se vincula con el citado estudio sobre la igualdad y en algún sentido erigir un lenguaje constituyente, con voz propia, dentro de la teoría constitucional. Obviamente, ambos textos se empalman y complementan.

49 El "Preámbulo" de la Constitución de la Organización Internacional del Trabajo (1919) sintetiza, en un texto difícil de superar por su hondura y su extremo cuidado, la ligazón entre coexistencia pacífica e inclusión social. Así, se lee y aprecia: “Considerando que la paz universal y permanente sólo puede basarse en la justicia social....". En 1944, la Conferencia General de la Organización Internacional del Trabajo, congregada en Filadelfia en su $26^{\text {a }}$ reunión, adopta, la Declaración de los fines y objetivos de la Organización Internacional del Trabajo y de los principios que debieran inspirar la política de sus Miembros. Allí, en el apartado II) se dispuso: "La Conferencia, convencida de que la experiencia ha demostrado plenamente cuán verídica es la declaración contenida en la Constitución de la Organización Internacional del Trabajo, según la cual la paz permanente sólo puede basarse en la justicia social afirma que: (a) todos los seres humanos, sin distinción de raza, credo o sexo tienen derecho a perseguir su bienestar material y su desarrollo espiritual en condiciones de libertad y dignidad, de seguridad económica y en igualdad de oportunidades; (b) el logro de las condiciones que permitan llegar a este resultado debe constituir el propósito central de la política nacional e internacional; (c) cualquier política y medida de índole nacional e internacional, particularmente de carácter económico y financiero, deben juzgarse desde este punto de vista y aceptarse solamente cuando favorezcan, y no entorpezcan, el cumplimiento de este objetivo fundamental; (d) incumbe a la Organización Internacional del Trabajo examinar y considerar, teniendo en cuenta este objetivo fundamental, cualquier programa o medida internacional de carácter económico y financiero; 
Si no se pretende quebrar la armonía y el equilibrio de la paz alcanzada como presupuesto fundamental del constitucionalismo, se deberá enfrentar el problema de la desigualdad. Porque el contra-paradigma de la desigualdad en los bienes y en la riqueza dibuja e instala una diversidad que tarde o temprano, siempre, termina por estallar en detrimento de la paz alcanzada, aquí, con injusticia social.

En las líneas anteriores quizá existe un germen de verdad. Si fuese así, será porque alguna razón y experiencia me pueden alumbrar en la existencia cotidiana, al igual que a todos los hombres, dado que son las fuentes del conocimiento científico. Nada de lo sostenido reposa en la fe.

No hay explosión más insensata que la ausencia de la paz. No hay experiencia más atroz que la guerra. La negación de la paz deshumaniza a los hombres y los convierte en ineptos para una existencia con vida digna. Sin paz, la Tierra se convierte en un sitio carente de hospitalidad. El mal que causa la guerra, la disputa bélica duradera y desalmada, resulta incurable y de imposible perdón. Siempre coloca al hombre en un camino sin fin.

La perspectiva laica desplegada en esta pieza posee un arraigado sentido del límite, porque no creo en ninguna divinidad providente metafísica de la paz y que cure al hombre del mal de la guerra. La experiencia de esta última vuelca al hombre como un ser incivilizado, enfermizo, marchito, nulo y efímero. Intuyo, por eso, que únicamente la paz puede atesorar la verificación y consagración de la hipótesis o afirmación capital: la concreta posibilidad de llevar adelante un plan de existencia de vida digna con cognición suficiente, en este tiempo y espacio de nuestro mundo.

y (e) al cumplir las tareas que se le confíen, la Organización Internacional del Trabajo, después de tener en cuenta todos los factores económicos y financieros pertinentes, puede incluir, en sus decisiones y recomendaciones, cualquier disposición que considere apropiada". (El autor agradece a Mario E. Ackerman su valiosísimo comentario respecto de las normas de la OIT y su relación con la paz y la justicia social). 
Así pues, la noción que echo a andar ciertamente concentra una expectativa de generalidad para América del Sur: la constitución, pese a ser nuestro único relato imperfecto, configura el único artefacto contundente que con sus procesos orientados a la paz puede dar respuesta a la evitación de la guerra, un mal que arroja al hombre al mundo como un mero ente bípedo, irracional, inexperiente e implume. No es un misterio: nuestra única "providencia" es la constitución y sus procesos, cuya religiosidad -"exactitud en hacer o cumplir algo"- acerca a la paz al hombre y a la comunidad que cada uno de ellos, con soberana individualidad, debe determinar y merece su inclusión sin discriminación arbitraria. 